\title{
COMPARATIVE STUDY BETWEEN SOLID STATE WELDING AND RADIANT ENERGY WELDING PROCESSES FOR JOINING METALLIC GLASSY RIBBONS
}

\author{
P. Hididis ${ }^{*}$, M. Nicolaescul , C. Codrean ${ }^{1}$, D. Buzdugan ${ }^{1}$, \\ I. V. Simiti ${ }^{2}$ V. A. Serban ${ }^{1}$ \\ ${ }^{1}$ Politehnica University of Timisoara, P-ta Victoriei, No. 2, Timisoara, Romania \\ ${ }^{2}$ Technical University of Cluj-Napoca, Memorandumului Street, No 28, Cluj-Napoca, Romania \\ *Corresponding author's e-mail address: petru.hididis@ student.upt.ro
}

\begin{abstract}
Amorphous alloys have emerged as an important class of advanced materials that own a combination of properties, such as mechanical strength, hardness, high elasticity modulus and a very good corrosion resistance. Since the number of amorphous structures alloys increased in the last decades, ways of joining such materials were studied in order to produce complex structures or increase their size. Thus, if this kind of complex products are obtained, it will diversify their applicability in multiple and various domains. For this research two ways of joining amorphous ribbons has been studied: solid state welding and radiant energy welding. For the radiant energy welding process, it was selected electron beam welding $(E B W)$ method and for the solid-state welding process, ultrasonic welding $(U W)$ method was chosen. Seeing that these methods have found applicability in industries, a comparative study was done in order to see which one offers the best outcome. Recently, in the last years, such products were embedded in a polymer matrix, creating thus, composite materials that have improved mechanical properties. This raised curiosity for major industries, such as aero-space, medical and automotive. Amorphous ribbons from $\mathrm{Ni}$ - $\mathrm{Fe}$ - $\mathrm{Cr}$-Si$B$ and Al-Ni-Nd-Co alloy families were welded by EBW method, and $\mathrm{Cu}-\mathrm{Zr}-\mathrm{Al}$ amorphous ribbons were welded by the UW method. Microstructure characterization has been performed by SEM, EDX, XRD and DSC analyses.
\end{abstract}

KEYWORDS: glassy ribbons, electron beam welding, ultrasonic welding.

\section{INTRODUCTION}

The first metallic glass alloy was discovered by Klement and Duwez in 1960. An alloy that has an amorphous structure and has been obtained by rapid cooling of a melt is a glassy alloy. They realized that a glassy structure can be obtained by rapid quenching of a melt. This was done on an Au-Si alloy under ribbons form. Having high cooling rates and a small thickness, ribbons with a fully glassy structure were produced [1]. This discovery has opened the door to countless possibilities for alloys that might produce products with a glassy structure and thus, became a field of research. As years passed by, and as research continued, it was discovered that glassy products have unique properties, e.g., high strength, high elastic limit and a very good wear resistance [2]-[4]. This led to application in various engineering fields. In recent times, the focus is to join such materials [5], [6]. But this is a delicate and intricate goal.
The most common welding methods are radiant energy welding process and solid-state welding. Nevertheless, there are multiple techniques that were developed: electron beam welding [7], spark welding [8], friction welding [7], laser welding [9], [10] and ultrasonic welding [11].

In this paper, a comparative study was performed using the electron beam welding and the ultrasonic welding, as representative welding methods based on radiant energy processes and solid-state welding respectively. EBSR offers various advantages over other welding processes, such as reduced distortion due to precise dosing of the energy during welding, minimal microstructural changes and low alteration of material characteristics [12]. EBW started being used due to the rapid development of its equipment, the high-quality requirements of the products that can be fulfilled, features of the process that offer unique solutions and the economic benefits when used for mass production [13]. This welding method uses the kinetic energy of the electron as the heating source in 
order to weld metals between them [13]. In order to generate kinetic energy a negatively charged filament is heated to its thermionic emission temperature range and in this way, electrons are emitted. The electrical field passes through the hole in the anode thus, forming a beam of accelerated electrons. In vacuum the beam can make contact with the metal's surface at speeds up to $70 \%$ of the speed of light and can reach diameters between 0.3 to $0.8 \mathrm{~mm}$. However, the main advantage of method is the deep and narrow weld that produces a minimal heat affected zone.

UW consists in pressing two (or more) samples with an ultrasonic horn with a predefined pressure and applying ultrasonic vibration that is parallel to the bonding interface [11]. The ultrasonic vibrations produce a mechanical friction thus generating heat that leads to bonds between the atoms by plastic deformation [14]. For both methods, there is the possibility of producing bulk metallic glasses (BMG), by overlapping multiple ribbons and obtaining BMGs with various shapes or thicknesses. Moreover, combining different materials between them is possible by using these welding techniques. For example, joining dissimilar metals [15] and nanocrystalline alloys [16]. Recent studies have been made in solidstate bonding of metallic glass and crystalline metals [17] and also discoveries have been made of multifunctional glass-glass composites by atomic scale stress relaxation under ultrasonic vibrations [18].

The present study consists in a comparative study between glassy ribbons that were produced using the melt spinning technique, having their glassy structure confirmed by XRD analysis. For both methods, the impact of the weld on the structure of the ribbons was studied. SEM investigations were made in order to see the deformations on the area where the ribbons were welded. Their glass forming ability (GFA) was compared to see which method proposes a better performing chemical composition.

\section{EXPERIMENTAL PROCEDURE}

For the comparative study, 3 types of alloys were designed and obtained, with different chemical compositions, as follows:

- for EBW process - $\mathrm{Al}_{65.22} \mathrm{Ni}_{15.02} \mathrm{Nd}_{16.41} \mathrm{Co}_{3.35}$ and $\mathrm{Ni}_{87.2} \mathrm{Fe}_{4.2} \mathrm{Cr}_{1.3} \mathrm{Si}_{4.5} \mathrm{~B}_{2.8}$

- for UW process - $\mathrm{Cu}_{45} \mathrm{Zr}_{45} \mathrm{Al}_{5} \mathrm{Ag}_{5}$ and $\mathrm{Ni}_{87.2} \mathrm{Fe}_{4.2}$ $\mathrm{Cr}_{1.3} \mathrm{Si}_{4.5} \mathrm{~B}_{2.8}$.

Master alloys were produced using the vacuum arc remelting technique using a MRF ABJ 900 equipment in order to melt chemical components that have a purity of $99.9 \%$, using a water-cooled tungsten electrode. It was taken into consideration the degree of assimilation of the used elements in order to estimate the volume of the mini-ingots. High purity argon 5.3 was assured by the installation at a level of $1,1 \mathrm{~atm}$ for $20 \mathrm{~min}$ to purify the chamber and also as a protective atmosphere. Oxygen level of $60 \mathrm{ppm}$ was established in the chamber. Button shaped master alloys (of $20 \mathrm{~g}$ ) were then inserted in a quartz crucible (Ilmasil PN). The ribbons with a thickness of $20 \mu \mathrm{m}$ were obtained by the melt spinning method in an open environment.

In order to weld a number of five overlapped ribbons by $\mathrm{UW}$, a $3000 \mathrm{~W}$ generator that resonates at a frequency of $20 \mathrm{KHz}$ is used. The ultrasonic horn is made out of C45R quality heat treated steel.

For the EBW process, the overlapped ribbons were kept in place by blocks of titanium that have a cut-out for the electrons beam. The values of the process parameters in the case of the UW process are presented in table 1, while for the EBW process are shown in table 2 .

Table 1. Input parameters for UW samples

\begin{tabular}{|c|c|c|c|c|c|}
\hline Sample & $\begin{array}{c}\text { Amplitude } \\
(\mathbf{A} / \boldsymbol{\mu m})\end{array}$ & $\begin{array}{c}\text { Welding time } \\
(\mathbf{T} / \mathbf{s})\end{array}$ & $\begin{array}{c}\text { Pressing } \\
\text { force } \\
(\mathbf{m B a r})\end{array}$ & $\begin{array}{c}\text { Frequency } \\
(\mathbf{f} / \mathbf{k H z})\end{array}$ & $\begin{array}{c}\text { Number } \\
\text { of welded } \\
\text { ribbons }\end{array}$ \\
\hline $\mathbf{C u}_{45} \mathbf{Z r}_{45} \mathbf{A l}_{5} \mathbf{A g}_{5}$ & 20 & 0.3 & 2.1 & 20 & 6 \\
\hline $\mathbf{N i}_{87.2} \mathbf{F e}_{4.2} \mathbf{C r}_{1.3} \mathbf{S i}_{4.5} \mathbf{B}_{2.8}$ & 20 & 0.3 & 2.1 & 20 & 4 \\
\hline
\end{tabular}

Table 2. Input parameters for EBW samples

\begin{tabular}{|c|c|c|c|c|c|}
\hline Sample & $\begin{array}{c}\text { Beam } \\
\text { Current } \\
(\mathbf{m A})\end{array}$ & $\begin{array}{l}\text { Acceleration } \\
\text { Voltage }(\mathbf{k V})\end{array}$ & $\begin{array}{l}\text { Welding } \\
\text { speed } \\
(\mathrm{mm} / \mathrm{s})\end{array}$ & $\begin{array}{c}\text { Specific heat } \\
\text { input } \\
(\mathbf{m} \mathbf{J} / \mathbf{m m})\end{array}$ & $\begin{array}{c}\text { Number } \\
\text { of welded } \\
\text { ribbons }\end{array}$ \\
\hline $\mathrm{Al}_{65.22} \mathrm{Ni}_{15.02} \mathrm{Nd}_{16.41} \mathrm{Co}_{3.35}$ & 3 & 120 & 10000 & 36 & 5 \\
\hline $\mathrm{Ni}_{87.2} \mathrm{Fe}_{4.2} \mathrm{Cr}_{1.3} \mathrm{Si}_{4.5} \mathrm{~B}_{2.8}$ & 3.5 & 120 & 10000 & 42 & 6 \\
\hline
\end{tabular}

On a macroscopic level it appears that all batches of ribbons were successfully welded. Macro images of the UW samples are represented in figure 1 and for EBW are inserted in figure 2. But to confirm their structure before and after welding, X-ray diffractometry was realized using a $\mathrm{Co}-\mathrm{K} \alpha$ radiation $(\lambda=1.78901 \mathrm{~nm})$ operated at $40 \mathrm{Kv}$ and $40 \mathrm{Ma}$ on a Philips PW3064. DSC analyses were performed on a NETZSCH STA 449F1 equipment using a heating rate of $20 \mathrm{~K} / \mathrm{min}$ in an $\mathrm{Al}_{2} \mathrm{O}_{3}$ crucible under $\mathrm{N}_{2}$ atmosphere 
at a temperature range from $20^{\circ} \mathrm{C}$ to $700{ }^{\circ} \mathrm{C}$. The microstructural investigations in the welding area were performed on a FEI Inspect-S scanning electron microscope. An EDAX Ametek Element Module was used to perform a chemical characterization of the samples.

a)

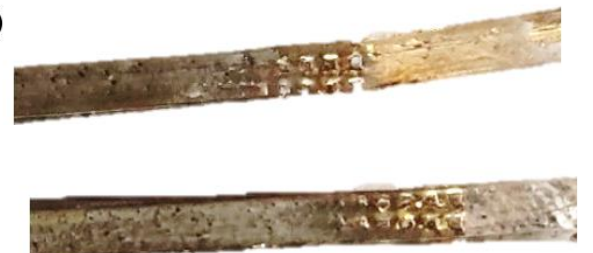

$|2 \mathrm{~mm}|$

b)

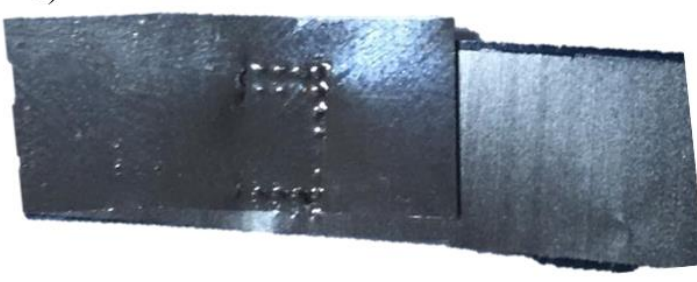

$2 \mathrm{~mm}$

Fig. 1. Images of UW samples, a) $\mathrm{Cu}-\mathrm{Zr}$ based sample, b) Ni-Fe based sample
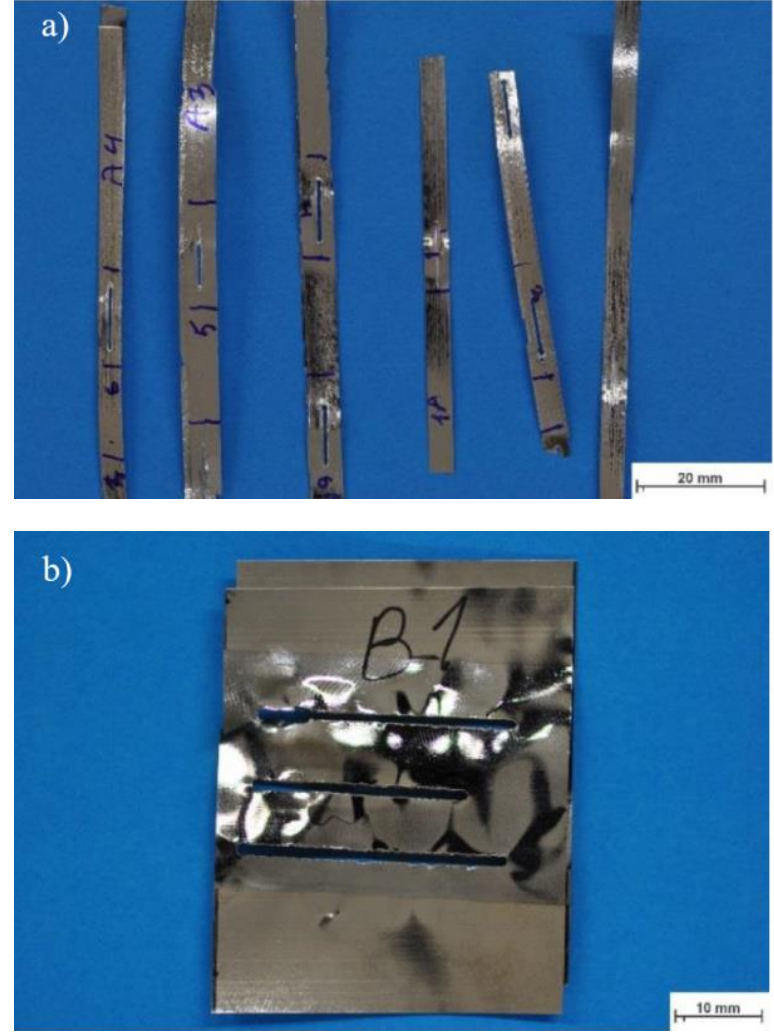

Fig. 2. Images of EBW samples: a) Al-Ni based b) $\mathrm{Ni}-\mathrm{Fe}$ based

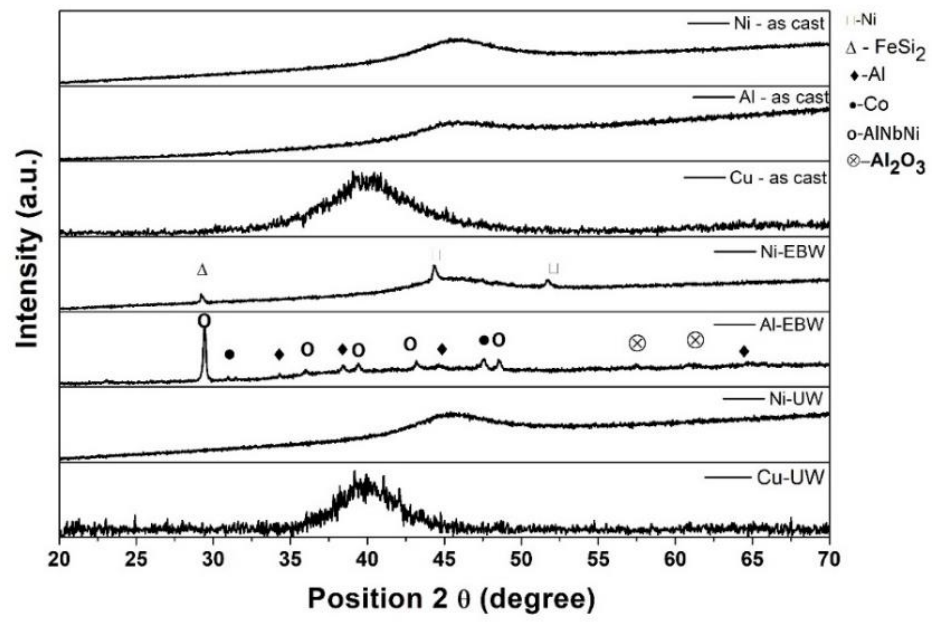

Fig. 3. X-ray diffraction patterns of the ribbons before and after welding

\section{RESULTS AND DISCUSSION}

The following coding was used for an easier and faster way of recognizing samples: Al-EBW and Al-UW for $\mathrm{Al}_{65.22} \mathrm{Ni}_{15.02} \mathrm{Nd}_{16.41} \mathrm{Co}_{3.35} ; \mathrm{Ni}-\mathrm{EBW}$ and $\mathrm{Ni}-\mathrm{UW}$ for $\mathrm{Ni}_{87.2} \mathrm{Fe}_{4.2} \mathrm{Cr}_{1.3} \mathrm{Si}_{4.5} \mathrm{~B}_{2.8}$ and $\mathrm{Cu}-\mathrm{UW}$ for $\mathrm{Cu}_{45} \mathrm{Zr}_{45} \mathrm{Al}_{5} \mathrm{Ag}_{5}$ becomes $\mathrm{Cu}-\mathrm{UW}$. The microstructure of the samples was analyzed both before and after welding. Figure 3 show the X-ray diffraction patterns for the samples. The first three rows are for the as cast samples, and the broad diffraction maxima confirms their glassy structure.
The next rows from figure 3 show the structure analysis of the welded area. Rows 4 and 5 are the diffraction patterns for EBW for the $\mathrm{Al}_{65.22} \mathrm{Ni}_{15.02} \mathrm{Nd}_{16.41} \mathrm{Co}_{3.35}$ and for $\mathrm{Ni}_{87.2} \mathrm{Fe}_{4.2} \mathrm{Cr}_{1.3} \mathrm{Si}_{4.5} \mathrm{~B}_{2.8}$ samples. It shows that the glassy structure of the ribbons is not maintained after the EBW process. The Ni-EBW sample suggests a feeble pattern of glassy structure, but it shows that there are strong crystalline peaks. After analysis it was found that the crystalline peaks are $\mathrm{Ni}$ phases. Regarding the Al-EBW, multiple crystalline peaks are observed. The phases that form after the welding 
process are $\mathrm{FeSi}_{2}, \mathrm{AlNbNi}, \mathrm{Co}, \mathrm{Al}$, and $\mathrm{Al}_{2} \mathrm{O}_{3}$. These patterns after EBW suggest that the heat generated by the beam of electrons is too high and modifies the structure of the ribbons. The final two rows show that the UW keeps intact the glassy structure of the ribbons in the area of the welded joint.

On the welded area for each composition DSC analyses were performed at a temperature range from $20{ }^{\circ} \mathrm{C}$ to $700^{\circ} \mathrm{C}$. The glass transition temperature $\left(\mathrm{T}_{\mathrm{g}}\right)$ and crystallization temperature $\left(\mathrm{T}_{\mathrm{x} 1}\right.$ and $\left.\mathrm{T}_{\mathrm{x} 2}\right)$ values are inserted in table 3 . The supercooled liquid region is calculated in the last column of the table [19].

Table 3. DSC values of of UW welds

\begin{tabular}{|c|c|c|c|c|}
\hline Sample & $\mathbf{T}_{\mathbf{g}}$ & $\mathbf{T}_{\mathbf{x} 1}$ & $\mathbf{T}_{\mathbf{x} 2}$ & $\Delta \mathbf{T}_{\mathbf{x}}$ \\
\hline $\mathbf{N i}-\mathbf{U W}$ & 357.2 & 459.9 & 515.4 & 130.45 \\
\hline $\mathbf{C u}-\mathbf{U W}$ & 372 & 484 & - & 112 \\
\hline
\end{tabular}

From figure 4 it can be seen clearly that under EBW the samples did not manifest any glass transition temperature, thus confirming the results from the XRD in which their crystalline structure is shown. Regarding UW, both samples manifest glass transition followed by an immediate crystallization suggested in figure by the arrows. The $\mathrm{Ni}$ bases sample show two crystallization peaks. This is due to one of the chemical components that crystallizes at higher temperatures. Higher values for the supercooled liquid region are recorded for the $\mathrm{Cu}$ based alloy, being due to a more stable and densely packed liquid structure.

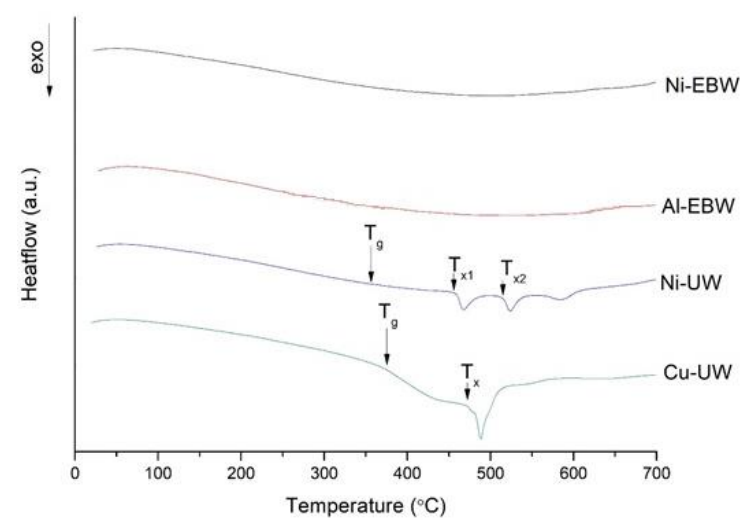

Fig. 4. DSC comparison of the samples before and after welding

In order to investigate the microstructure of the welded joints using SEM, the samples were embedded and afterwards grinded and polished in order to obtain a clear and planar view of the bonds between the ribbons. Figure 5 show SEM micrographs of the welded areas. From the figure 5 a can be observed the formation of a common nucleus resulting from the melting of 6 overlapping bands of Ni-EBW alloy. The molten area has an asymmetry at the base, with the leak tendency of the molten metal, which shows that the parameters of the welding regime had excess values. At the same time, there is a fragmentation of a strip and a crack in the left side of the package, due to the mechanical tensions inherent in welding and blocked expansion. A similar situation can be observed in figure $5 \mathrm{~b}$, where the microstructure of the molten nucleus, obtained by overlapping of 5 strips, has a dendritic appearance, with needles-like compounds. Also, the contraction during solidification favored the formation of a reduction of the core section, similar to the open shrinkage of the castings.
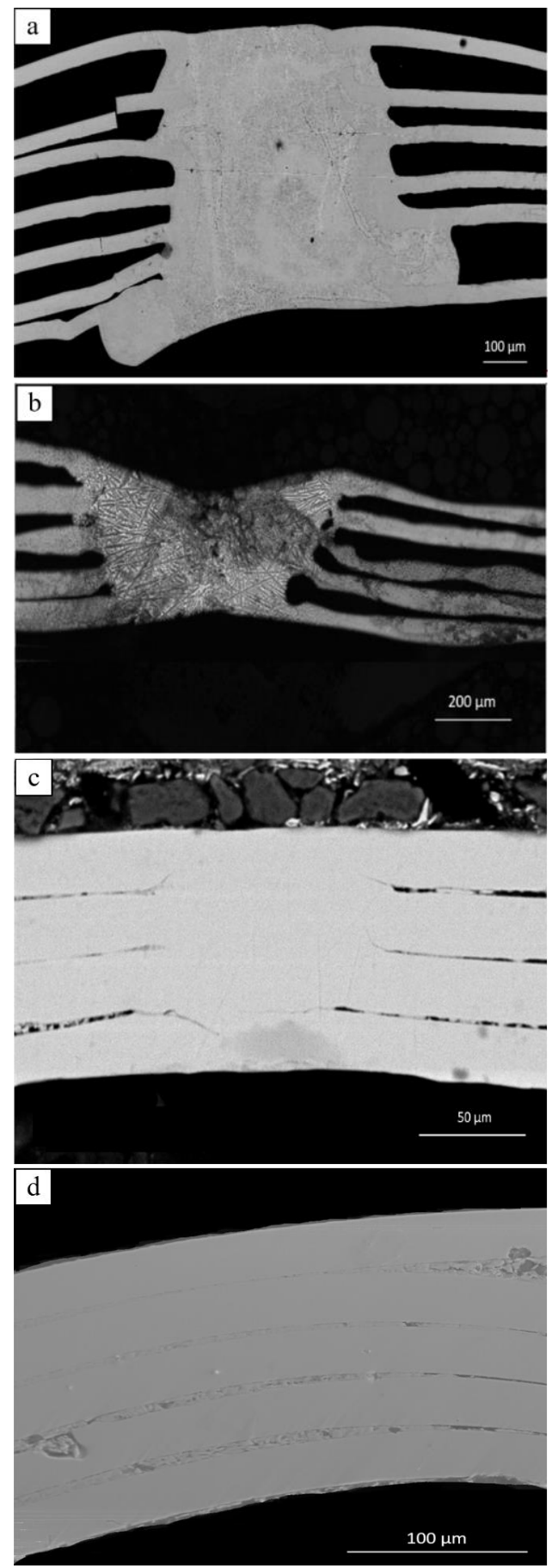

Fig. 5. SEM investigations on the welded area of the samples 
Figure 5c shows the formation of a common nucleus without deformations, whose microstructure does not seem to have undergone major transformations and recrystallization. It is the most accurate welded joint obtained in the study.

Figure $5 \mathrm{~d}$ is somewhat similar to figure $5 \mathrm{C}$, except that in this case the complete assembly of the overlapping strip package was not performed, there

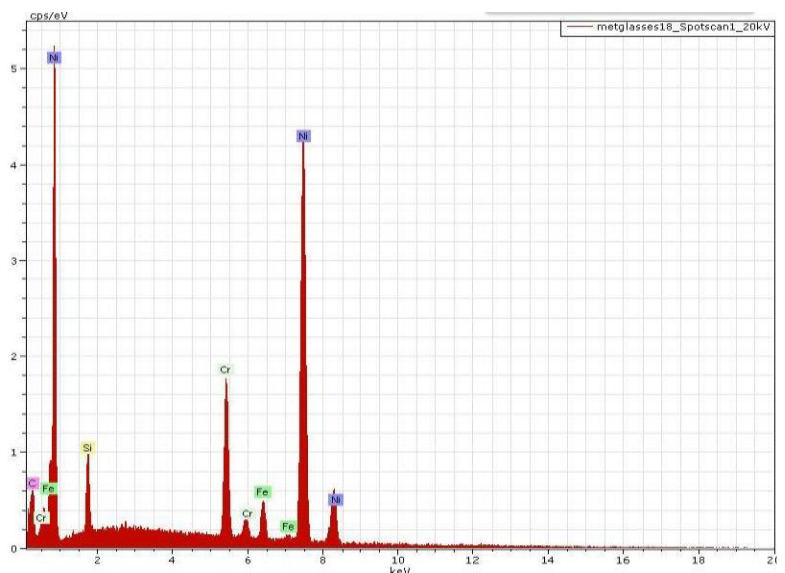

a)

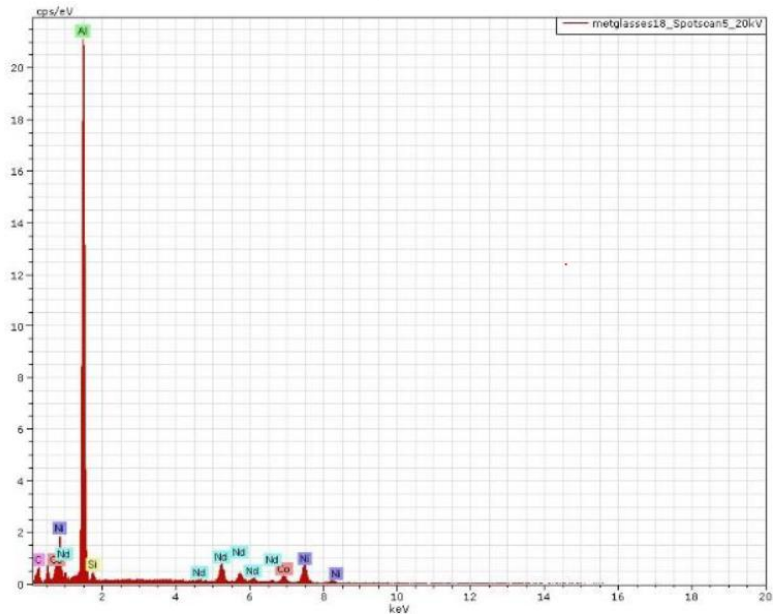

b) being areas that do not show sufficient adhesion. However, the presence of a crystalline structure with a dendritic appearance in the welded joints can be noticed. Figure $5 \mathrm{c}$ is for Ni-UW and $5 \mathrm{~d}$ is for $\mathrm{Cu}-\mathrm{UW}$ and confirms that multiple ribbons can be welded using the UW equipment. The UW shows a more uniform distribution of the weld and the ribbon's shape appear unaffected in the region where the weld was realized.

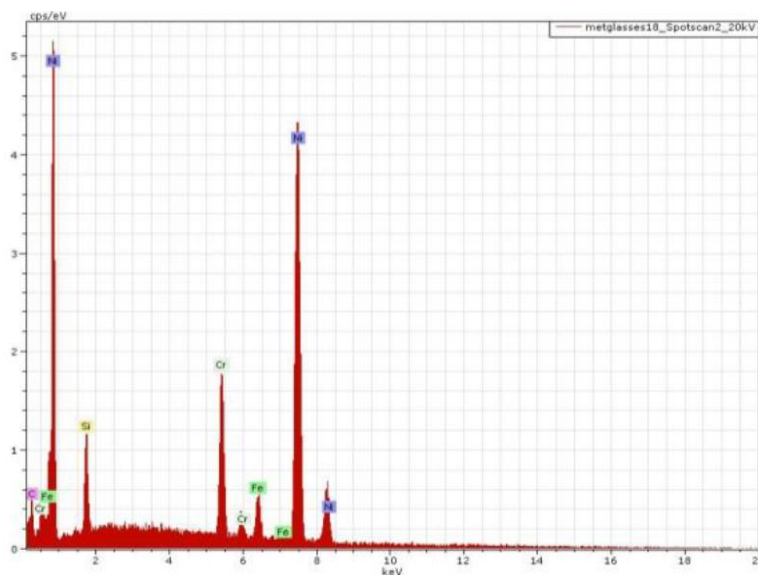

c)

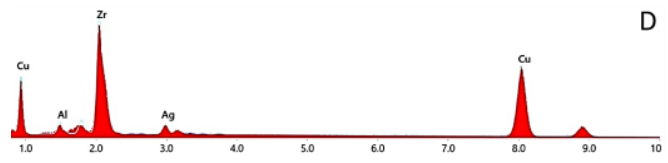

d)

Fig. 6. EDX chemical elements spectrum on the weld nucleus

The EDX spectrums represented in figure 6 correspond to the same notations from figure 5 regarding the chemical composition and the joining method. EDX was done on the weld nucleus for each sample. Figure 6a show strong values of $\mathrm{Ni}$ and $\mathrm{Cr}$ alongside with smaller peaks of $\mathrm{Si}, \mathrm{Fe}$ and $\mathrm{B}$. In figure $6 \mathrm{~b}$ a strong $\mathrm{Al}$ values is observed. The EDX from figures $6 c$ and $6 d$ confirm the presence of all chemical elements. The elements that have a higher value is due to a higher percentage within the composition.

\section{CONCLUSIONS}

After successfully producing ribbons with a metallic glassy structure using the melt spinning technique in an open environment, multiple overlapped ribbons for each chemical composition were welded. The methods that were used are EBW and UW. Afterwards a comparative study between the two methods was done.

Investigation of welded nucleuses by using XRD, DSC and SEM analysis methods show that the structure of the ribbons remains unaffected after the UW technique. But after EBW multiple crystalline peaks appear. The heat that was produced by the ultrasonic horn had no effect on the structure. It appears that generated heat produced by the electron beam was too high and contributed to modification within the structure. In the case of the UW method the weld appears to be more uniform and the shape of the ribbons at the extremities of the weld have not been modified. The values of the chemical compositions of the elements identified in fig. 6 must be analyzed, in comparison with the base materials. Explanations must be provided about the differences in chemical 
composition that appeared due to the welding conditions.

In conclusion, after the comparative study, seeing that the structure of the ribbons is kept intact after the UW and the shape of the weld is more uniform, it is recommended to use UW as a way of joining glassy ribbons. Future investigations will consist in welding ribbons in more complex shapes so as to increases their applicability.

\section{REFERENCES}

[1] Klement W., Willens R. H., Duwez P. O. L., Non-crystalline Structure in Solidified Gold-Silicon Alloys, Nature, 1960, vol. 187(4740), pp. 869-870.

[2] Huang, Y., et al., The onset of plasticity of a Zr-based bulk metallic glass, International Journal of Plasticity, 2014, vol. 60, pp. 87-100.

[3] Johnson W. L., Bulk Glass-Forming Metallic Alloys, Science and Technology, MRS Bulletin, 1999, vol. 24(10), pp. 42-56.

[4] Wan W. H., Dong C., Shek C. H., Bulk metallic glasses, Materials Science and Engineering, R: Reports, 2004, vol. 44(2), pp. 45-89.

[5] Gallego-Juarez J. A., Graff K. F., Power Ultrasonics, Applications of High-Intensity Ultrasound, 2014, Elsevier Science. [6] Mattson J., Theisen E., Steen P., Rapid solidification forming of glassy and crystalline ribbons by planar flow casting, Chemical Engineering Science, 2018, vol. 192, pp. 1198-1208.

[7] Kim J., Kawamura Y., Electron beam welding of the dissimilar Zr-based bulk metallic glass and Ti metal, Scripta Materialia - SCRIPTA MATER, 2007, vol. 56, pp. 709-712.

[8] Kawamura Y., Ohno Y., Spark welding of Zr55Al10Ni5Cu30 bulk metallic glasses, Scripta Materialia, 2001, vol. $45(2)$, pp. 127-132.
[9] Kawahito Y., et al., High-power fiber laser welding and its application to metallic glass Zr55Al10Ni5Cu30, Materials Science and Engineering: B, 2008, vol. 148(1), pp. 105-109.

[10] Kim J., et al., Phase evolution in Cu54Ni6Zr22Ti18 bulk metallic glass Nd:YAG laser weld, Materials Science and Engineering: A, 2006, vol. 434(1), pp. 194-201.

[11] Maeda M., et al., Ultrasonic bonding of Zr55Cu30Ni5Al10 metallic glass, Materials Science and Engineering: B, 2008, vol. 148(1), pp. 141-144.

[12] Nahmany M., et al., Al x CrFeCoNi High-Entropy Alloys: Surface Modification by Electron Beam Bead-on-Plate Melting, Metallography, Microstructure, and Analysis, 2016. 5.

[13] Sun Z., Karppi R., The application of electron beam welding for the joining of dissimilar metals: an overview, Journal of Materials Processing Technology, 1996, vol. 59(3), pp. 257-267.

[14] Song X., Zhu Z., Chen Y., Ultrasonic Welding of Fe78Si9B13 Metallic Glass, Materials Science Forum, 2015, vol. 809, pp. 348-353.

[15] Patel V. K., Bhole S. D., Chen D. L., Ultrasonic Spot Welding of Aluminum to High-Strength Low-Alloy Steel: Microstructure, Tensile and Fatigue Properties, Metallurgical and Materials Transactions A, 2014, vol. 45(4), pp. 2055-2066.

[16] Ward A.A., et al., Grain growth during ultrasonic welding of nanocrystalline alloys, Journal of Materials Processing Technology, 2018, vol. 254, pp. 373-382.

[17] Li G., et al., Experiments on the Ultrasonic Bonding Additive Manufacturing of Metallic Glass and Crystalline Metal Composite. Materials, 2019, vol. 12(18), pp. 2975.

[18] Ma J., et al., Fast surface dynamics enabled cold joining of metallic glasses. Science Advances, 2019, vol. 5(11), pp. eaax7256.

[19] Lu Z.P., Liu C.T., A new glass-forming ability criterion for bulk metallic glasses. Acta Materialia, 2002, vol. 50(13), pp. 35013512 . 